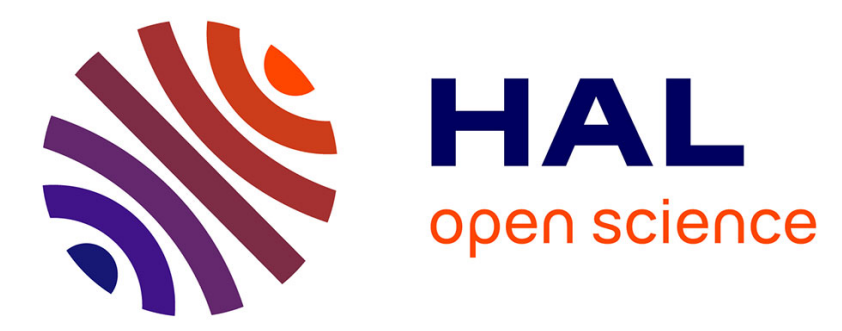

\title{
Propofol as an induction agent for endotracheal intubation can cause significant arterial hypotension in preterm neonates
}

Lars Welzing, Angela Kribs, Frank Eifinger, Christoph Huenseler, Andre

Oberthuer, Bernhard Roth

\section{To cite this version:}

Lars Welzing, Angela Kribs, Frank Eifinger, Christoph Huenseler, Andre Oberthuer, et al.. Propofol as an induction agent for endotracheal intubation can cause significant arterial hypotension in preterm neonates. Pediatric Anesthesia, 2010, 20 (7), pp.605. 10.1111/j.1460-9592.2010.03330.x . hal-00552645

\section{HAL Id: hal-00552645 \\ https://hal.science/hal-00552645}

Submitted on 6 Jan 2011

HAL is a multi-disciplinary open access archive for the deposit and dissemination of scientific research documents, whether they are published or not. The documents may come from teaching and research institutions in France or abroad, or from public or private research centers.
L'archive ouverte pluridisciplinaire HAL, est destinée au dépôt et à la diffusion de documents scientifiques de niveau recherche, publiés ou non, émanant des établissements d'enseignement et de recherche français ou étrangers, des laboratoires publics ou privés. 


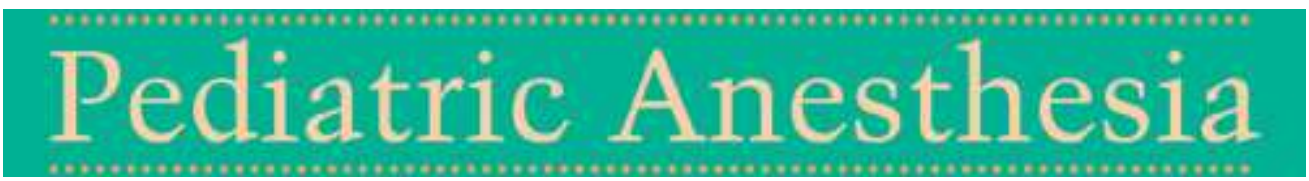

\section{Propofol as an induction agent for endotracheal intubation can cause significant arterial hypotension in preterm neonates}

\begin{tabular}{|c|c|}
\hline Journal: & Pediatric Anesthesia \\
\hline Manuscript ID: & PAN-2009-0342.R4 \\
\hline Manuscript Type: & Original Paper \\
\hline $\begin{array}{r}\text { Date Submitted by the } \\
\text { Author: }\end{array}$ & 07-Apr-2010 \\
\hline Complete List of Authors: & $\begin{array}{l}\text { Welzing, Lars; University Hospital of Cologne, Children's Hospital, } \\
\text { Department of Neonatology and Paediatric Intensive Care } \\
\text { Kribs, Angela; University Hospital of Cologne, Children's Hospital, } \\
\text { Department of Neonatology and Paediatric Intensive Care } \\
\text { Eifinger, Frank; University Hospital of Cologne, Children's Hospital, } \\
\text { Department of Neonatology and Paediatric Intensive Care } \\
\text { Huenseler, Christoph; University Hospital of Cologne, Children's } \\
\text { Hospital, Department of Neonatology and Paediatric Intensive Care } \\
\text { Oberthuer, Andre; University Hospital of Cologne, Children's } \\
\text { Hospital, Department of Neonatology and Paediatric Intensive Care } \\
\text { Roth, Bernhard; University Hospital of Cologne, Children's Hospital, } \\
\text { Department of Neonatology and Paediatric Intensive Care }\end{array}$ \\
\hline Key Words: & $\begin{array}{l}\text { preterm infants, propofol, induction agent, intubation, arterial } \\
\text { hypotension }\end{array}$ \\
\hline
\end{tabular}

\section{scholarONE" \\ Manuscript Central}




\section{Propofol as an induction agent for endotracheal intubation can cause significant arterial hypotension in preterm neonates}

Lars Welzing MD, Angela Kribs MD, Frank Eifinger MD, Christoph Huenseler MD, Andre Oberthuer MD, Bernhard Roth MD

University Hospital of Cologne, Children's Hospital, Department of Neonatology and Paediatric Intensive Care, Germany

Corresponding author:

Lars Welzing

University of Cologne, Children’s Hospital,

Department of Neonatology and Paediatric Intensive Care,

Kerpener Str. 62, 50937 Cologne, Germany,

e-mail: 1ars.welzing@uk-koeln.de 


\begin{abstract}
Backround: Propofol is gaining increasing popularity as induction agent for paediatric endotracheal intubation. Recently propofol has been described for the first time as induction agent for endotracheal intubation in preterm neonates. Propofol seemed to be efficient, safe and ideally suited for the INSURE (Intubation SURfactant Extubation) procedure in preterm neonates. The purpose of this study was to document intubating conditions, vital signs, extubation times and outcome in preterm neonates receiving propofol as induction agent for the INSURE procedure.

Patients and Methods: Preterm neonates with a gestational age of 29 to 32 weeks and respiratory distress were eligible for INSURE with propofol if their postnatal age was less than 8 hours. Exclusion criteria were any kind of disease not allowing early extubation.

Results: There were 13 inborn neonates enrolled for INSURE, mean gestational age was 30 weeks +3 days and mean birth weight was $1428 \mathrm{~g}$ (range 1170-1780 g). We stopped our observational study ahead of time due to significant cardiovascular side effects. Propofol generally offered good intubating conditions, but we encountered severe problems with arterial hypotension. A low propofol bolus of $1 \mathrm{mg} / \mathrm{kg}$ caused a distinctive decline of mean arterial blood pressure from $38 \mathrm{mmHg}$ (range $29-42 \mathrm{mmHg}$ ) prior premedication to $24 \mathrm{mmHg}$ (22-40 mmHg) 10 minutes after propofol application.

Conclusions: Our experience with propofol as induction agent for endotracheal intubation in preterm neonates reveals distinctive cardiovascular effects which represent an important risk factor for serious complications of prematurity like intraventricular haemorrhage or periventricular leucomalacia. Propofol should be used with caution in very preterm neonates with respiratory distress during the first hours of life.
\end{abstract}

\title{
Key Words
}

propofol, preterm neonates, induction agent, intubation, arterial hypotension 


\section{Introduction}

Endotracheal intubation with subsequent surfactant application is a well established therapy for infant respiratory distress syndrome $(1,2)$. Recent evidence shows that premedication for nonemergency neonatal intubation is safer and more effective than awake intubation $(3,4)$. Various drugs like morphine, fentanyl, diazepam, midazolam or ketamine have been used as induction agent, although none these substances is ideal for preterm neonates $(5,6)$. An ideal drug should provide rapid induction, good intubating conditions, cardiopulmonary stability and rapid recovery, as preterm neonates are an especially vulnerable subgroup of patients. Typical complications associated with cardiopulmonary instability are for example intraventricular haemorrhage (IVH) or periventricular leucomalacia (PVL) (7).

Recently Ghanta et al (8) reported about the use of propofol as induction agent for endotracheal intubation in preterm neonates with a gestational age of 25 to 30 weeks. Propofol did not cause significant adverse effects and induced satisfactory hypnosis while spontaneous respiration was maintained throughout the intubation procedure at a dose of 2.5 $\mathrm{mg} / \mathrm{kg}$. Further studies were recommended to assess the safety of propofol.

Based on these results we conducted a prospective observational study with propofol for the INSURE (Intubation SURfactant Extubation) procedure, as in preterm neonates the period of mechanical ventilation should be kept as short as possible. Even a few days of mechanical ventilation are associated with an increased inflammatory response in the lungs, a weaker respiratory drive, peribronchiolar alveoloar wall thickening and a higher risk for cerebral injury $(9,10)$. INSURE was first described in 1990 by Victorin et al. and combines endotracheal intubation with surfactant application and early extubation (11). Subsequently many studies have proven the positive effect of INSURE on neonatal outcome $(12,13)$. Neonates are usually anaesthetized with morphine followed by naloxone application to reverse respiratory depression (13). However, morphine provides insufficient analgesia for intubation purposes in preterm neonates, and repeated doses of naloxone may be necessary to 
reverse respiratory depression as morphine has a long half-life of 9 hours in preterm neonates $(14,15)$. Furthermore, naloxone has been reported as associated with cardiac arrest in one preterm neonate (16).

The purpose of this study was to document intubating conditions, vital signs, extubation times and outcome in preterm neonates receiving propofol as induction agent for the INSURE procedure.

\section{Patients and Methods}

We conducted this observational study at the Department of Neonatology and Paediatric Intensive Care at the University Hospital of Cologne in an eight month period between September 2008 and April 2009. The study was approved by the Ethical Review Board of the Medical Faculty of the University of Cologne.

All preterm neonates with a gestational age of 29 to 32 weeks were eligible if their postnatal age was less than 8 hours and they exhibited moderate to severe respiratory distress at a postnatal age of at least 30 min. Respiratory distress was defined by $\mathrm{FiO} 2 \geq 0.3$ during CPAP to reach a postductal oxygen saturation $\geq 88 \%$ or by a Silverman Score $\geq 6$. The Silverman Score evaluates chest movements, intercostal retractions, xiphoid retractions, nasal flaring and expiratory grunting (17). Each parameter is allocated a score of $0-2$, total score is minimum 0 and maximum 10. A high score indicates severe respiratory distress. Exclusion criteria were any kind of disease not allowing early extubation (e.g. severe sepsis).

All included neonates were treated, according to our standard procedure, with CPAP $\geq 6 \mathrm{~cm}$ H2O immediately after birth based on Benvenistes paediatric gas-jet valve (Dameca, Copenhagen, Denmark). The Benveniste valve generates positive airway pressures of 6 to 10 $\mathrm{cm} \mathrm{H} 2 \mathrm{O}$ by creating a narrow stream of humidified air mixed with oxygen at a flow rate of 12 to 16 liters per minute (18). FiO2 was started at 0.5 and adjusted to reach an oxygen saturation 
between 88 to $96 \%$. An intravenous line was placed at the age of 10 minutes and we infused a glucose containing balanced salt solution at a rate of 3-4 ml/h.

At a postnatal age of at least 30 minutes we decided, according to the inclusion and exclusion criteria mentioned before, whether INSURE should be performed or not. Premedication for the INSURE procedure included atropine $10 \mu \mathrm{g} / \mathrm{kg}$ followed by propofol (Propofol $1 \%$, Fresenius Kabi, Sweden) within one minute. In our own experience with propofol $2.5 \mathrm{mg} / \mathrm{kg}$ we observed severe arterial hypotension refractory to correction with intravenous fluid administration. Therefore we used a propofol dose of $1 \mathrm{mg} / \mathrm{kg}$. As a bolus dose of $1 \mathrm{mg} / \mathrm{kg}$ caused significant arterial hypotension in the first six patients, defined as mean arterial blood pressure $<25 \mathrm{mmHg}$, we finally infused propofol $1 \mathrm{mg} / \mathrm{kg}$ over 60 seconds.

Vital parameters were taken both one minute prior and one minute after atropine and propofol application. Subsequently nasal intubation was performed around 75 seconds after the propofol application by physicians of varying experience (resident, neonatal fellow or consultant neonatologist). Each intubation was supervised by a consultant neonatologist, who took over the intubation process in case the first attempt by a resident or neonatal fellow failed. The children were in supine position with the head slightly elevated. We used a straight-blade laryngoscope (Miller00, Heine Optotechnik, Herrsching, Germany) and an uncuffed, nasotracheal tube without stylette (Vygon, 2.5 mm inner diameter, Écouen, France). After intubation tube position was evaluated by auscultation of the chest and subsequently surfactant $100 \mathrm{mg} / \mathrm{kg}$ was administered over 1-2 minutes. Afterwards the neonate was mechanically ventilated until respiratory drive was judged to be satisfactory for continuing CPAP therapy.

Intubating conditions were classified by our own scoring system rating limb movements, coughing and breathing. In our opinion established scoring systems describing variables like jaw relaxation or vocal cords position are not very useful in preterm neonates (19). Limb movements, coughing and breathing were allocated a score of 0-2 (table 1). Intubating 
conditions were judged excellent when total score was $\leq 1$ and good when total score was 2-3. Any assessment score $>3$, distinct limb movements or distinct coughing were taken as indicative of unacceptable conditions.

A clinically uninvolved member of the team was designated as an observer, data recorder and timekeeper. Heart rate, oscillometric blood pressure and postductal oxygen saturation were recorded 1 minute prior propofol application as well as 1, 5, 10, 20 and 30 minutes afterwards (Philips, Sure Signs VM6). Based on our clinical experience and the gestational age of our study population, we defined arterial hypotension as mean arterial blood pressure $<25$ mmHg. In our opinion $25 \mathrm{mmHg}$ represents a treshold for preterm infants of $29-32$ gestational weeks, as arterial hypotension is a known risk factor for serious complications like IVH and PVL, especially on the first day of life. Treatment included an intravenous sodium chloride bolus of $10 \mathrm{ml} / \mathrm{kg}$, which was repeated in case mean arterial blood pressure remained below $25 \mathrm{mmHg}$.

After discharge we analysed pulmonary outcome by documentation of days on mechanical ventilation, days on CPAP, duration of supplemental oxygen, incidence of pneumothorax and incidence of BPD defined as FiO2 $>0.21$ with 36 weeks of gestation. For general neonatal outcome all infants were evaluated for survival, intraventricular haemorrhage (IVH), periventricular leucomalacia (PVL), necrotizing enterocolitis (NEC) and retinopathy of prematurity (ROP).

\section{Statistical Analysis}

There was no predefined formal stopping rule concerning adverse events. Facing an unexpected high number of cases with severe arterial hypotension, defined as mean arterial blood pressure $<25 \mathrm{mmHg}$, we performed a post hoc explorative analysis as an alias for a stopping rule by realizing the following procedure: based on the null-hypothesis that the rate $\pi$ of arterial hypotension does not exceed $10 \%$, we computed an exact binomial confidence 
interval (CLOPPER-PEARSON, 1934) and an associated p-value for the one-sided test alternative that $\pi$ will exceed $10 \%$ using AddPlan ${ }^{\circledR}$ (Adaptive Designs-Plans and Analyses Software, AddPlan GmbH, Cologne 2009).

\section{Results}

A total of 43 preterm neonates with a gestational age of 29 to 32 weeks were assessed for eligibility. Thereof 13 inborn neonates revealed moderate to severe respiratory distress and were enrolled for INSURE, mean gestational age was 30 weeks +3 days and mean birth weight was $1428 \mathrm{~g}$ (range 1170-1780 g).

Our pilot study was supposed to continue for 1 year, but we stopped it ahead of time due to clinically significant problems with arterial hypotension. In the first six patients a single propofol bolus of $1 \mathrm{mg} / \mathrm{kg}$ caused severe arterial hypotension with mean arterial blood pressure decreasing from $38 \mathrm{mmHg}$ (range $29-42 \mathrm{mmHg}$ ) prior premedication to $24 \mathrm{mmHg}$ (22-40 mmHg) $10 \mathrm{~min}$ after propofol administration (Fig 1). Three of six patients revealed mean arterial blood pressures below $25 \mathrm{mmHg}$. As an attempt to minimise cardiovascular adverse effects, propofol $1 \mathrm{mg} / \mathrm{kg}$ was infused over 60 seconds in the final seven patients. However, again two patients exhibited clinically significant arterial hypotension and mean arterial blood pressure decreased from $37 \mathrm{mmHg}(31-46 \mathrm{mmHg})$ prior premedication to 28 mmHg (18-39 mmHg) 5 min after propofol administration (Fig 2). Corresponding systolic blood pressures are demonstrated in Figure 3 and 4.

In total 5 of 13 patients (38\%) revealed severe arterial hypotension, defined as mean arterial blood pressure below $25 \mathrm{mmHg}$. An explorative post hoc stopping rule analysis using a onesample one-sided exact (binomial) test for rates resulted in a rejection of the null-hypothesis that the rate does not exceed $10 \%(\mathrm{p}=0.007)$. The observed rate is statistically significant and clinically unacceptable exceeding the threshold of 10\%: the exact test based 95\%-confidence interval due to CLOPPER-PEARSON for this rate is $14 \%-68 \%$. 
Heart rate (Fig 5) and oxygen saturation remained stable throughout the entire INSURE procedure, irrespective whether propofol was administered as a bolus or over 60 seconds. Intubation was successful in all 13 patients without the need for further intervention. Nine patients $(69 \%)$ were intubated at the first attempt, four patients $(31 \%)$ at the second. Failed intubations were due to residents in training and not due to insufficient analgesia or sedation. Overall, assessment of intubating conditions revealed excellent or good conditions in eleven (85\%) patients. Five of these patients had a score $\leq 1$ and six a score $2-3$. In two patients (15 $\%$ ) intubating conditions were inadequate due to distinct coughing and total score of these children was $\geq 3$. The scores obtained for each assessment category are shown in Table 1 .

Propofol caused only a short period of respiratory depression and CPAP, which was applied in all patients, could be started $25 \mathrm{~min}$ (2-120 $\mathrm{min}$ ) after surfactant administration. One child needed reintubation after completed INSURE procedure due to insufficient spontaneous breathing with subsequent mechanical ventilation for two days.

All preterm neonates survived, none developed IVH, PVL, NEC, ROP, BPD or pneumothorax. Average time of nCPAP therapy was 4.6 days (2-9 days) and the average time with supplemental oxygen therapy was 1.8 days (0-6 days).

\section{Discussion}

Propofol is gaining increasing popularity as induction agent for paediatric endotracheal intubation, however there are only limited experiences in neonates. Propofol produces rapid induction, obtunds the hypertensive response to tracheal intubation, reduces airway reactivity and has a short recovery time $(5,6,20,21)$. Recently Ghanta et al. (8) reported for the first time about the use of propofol as induction agent for endotracheal intubation in preterm neonates. Propofol induced satisfactory hypnosis while spontaneous respiration was maintained throughout the intubation procedure. Ghanta et al. observed no significant adverse effects. 
Based on these promising results propofol seemed to be ideally suited as induction agent for the INSURE procedure.

Our study population was comparable to the patients of Ghanta et al., respectively slightly more mature (30 versus 27 weeks of gestation). Due to our own experience with propofol 2.5 $\mathrm{mg} / \mathrm{kg}$ causing severe arterial hypotension, we decided to perform our study with as decreased propofol dose of $1 \mathrm{mg} / \mathrm{kg}$ as arterial hypotension is an important risk factor for complications of preterm neonates like intraventricular haemorrhage (IVH) or periventricular leucomalacia (PVL) (7). However, also with a small dose of $1 \mathrm{mg} / \mathrm{kg}$ propofol there was a high incidence of arterial hypotension, irrespective whether propofol was applied as bolus or short infusion over 60 seconds. In total 5 of our 13 patients (38\%) suffered from significant arterial hypotension, fortunately none of these cases was associated with persistent foetal circulation as described by Veyckemans (22). In particular as we administered a decreased propofol dose compared to Ghanta et al, we did not expect to encounter so distinctive problems with arterial hypotension, although it is a known adverse effect of propofol (22-24). A possible explanation could be the fact that our patients were intubated within the first hours of life, while the patients of Ghanta et al were intubated at a postnatal age of 4 days. Mean arterial blood pressure of preterm infants rises significantly from day 1 to day 7 after birth, which seems to be a normal adaptation of preterm neonates $(25,26)$. However, it might also reflect how fragile the cardiovascular system of preterm neonates is in the first hours after delivery. Therefore, the fact that all our patients received propofol within eight hours after birth, could explain our repeated problems with arterial hypotension.

Common adverse effects of propofol like hypotension, bradycardia and apnea may be exacerbated when propofol is administered in the presence of sepsis, hypovolemia or congenital heart disease. Propofol is a sedative agent and doses given when wrongly used to manage pain are greater than required for sedation. Higher doses are associated with increased 
adverse effects. Monitoring of vital signs and active management of adverse effects during administration is essential (27-29).

Propofol revealed excellent or good intubating conditions in 11 of 13 (85\%) patients. However, in two patients (15\%) the decreased propofol dose of $1 \mathrm{mg} / \mathrm{kg}$ was insufficient and provided inadequate intubating conditions. It seems that more mature preterm neonates sometimes require a propofol dose $>1 \mathrm{mg} / \mathrm{kg}$ for attaining good intubating conditions.

Propofol caused only a short period of respiratory depression in our preterm neonates, although it has a reduced clearance in neonates compared to toddlers and older children. This can be explained by the fact that reduction of propofol concentrations after induction is attributable to redistribution rather than clearance (30). On average CPAP could be continued 25 min after surfactant administration.

Fortunately none of our patients revealed serious complications of prematurity like IVH, PVL, NEC, BPD or ROP. However, although we investigated only a small sample size of 13 patients, in our opinion the repeated problems with significant arterial hypotension forbade continuation of the study and therefore we stopped it ahead of time.

In conclusion our experiences with propofol as induction agent for endotracheal intubation in preterm neonates of 29 to 32 gestational weeks with infant respiratory distress syndrome are alarming. The distinctive cardiovascular adverse effects of propofol represent an important risk factor for serious complications of prematurity like intraventricular haemorrhage or periventricular leucomalacia. Propofol should be used with caution in very preterm neonates with respiratory distress during the first hours of life. Further research is necessary concerning the use of propofol a few days after delivery and particular attention should be paid on cardiovascular adverse effects. 


\section{Acknowledgement}

We thank Dr. Hartmut Stuetzer from the University Hospital of Cologne, Institute of Medical Statistics, Informatics and Epidemiology, for support concerning statistical data analysis.

\section{Reference List}

(1) Fujiwara T, Konishi M, Chida S et al. Surfactant replacement therapy with a single postventilatory dose of a reconstituted bovine surfactant in preterm neonates with respiratory distress syndrome: final analysis of a multicenter, double-blind, randomized trial and comparison with similar trials. The Surfactant-TA Study Group. Pediatrics 1990 Nov;86(5): 753-764.

(2) Horbar JD, Soll RF, Sutherland JM et al. A multicenter randomized, placebocontrolled trial of surfactant therapy for respiratory distress syndrome. $N$ Engl J Med 1989 Apr 13;320(15): 959-965.

(3) Carbajal R, Eble B, Anand KJ. Premedication for tracheal intubation in neonates: confusion or controversy? Semin Perinatol 2007 Oct;31(5): 309-317.

(4) Duncan HP, Zurick NJ, Wolf AR. Should we reconsider awake neonatal intubation? A review of the evidence and treatment strategies. Paediatr Anaesth 2001 Mar;11(2): $135-145$.

(5) Simon L, Trifa M, Mokhtari M et al. Premedication for tracheal intubation: a prospective survey in 75 neonatal and pediatric intensive care units. Crit Care Med 2004 Feb;32(2): 565-568.

(6) Whyte S, Birrell G, Wyllie J. Premedication before intubation in UK neonatal units. Arch Dis Child Fetal Neonatal Ed 2000 Jan;82(1): F38-F41.

(7) Kuint J, Barak M, Morag I et al. Early treated hypotension and outcome in very low birth weight infants. Neonatology 2009;95(4): 311-316.

(8) Ghanta S, Abdel-Latif ME, Lui K et al. Propofol compared with the morphine, atropine, and suxamethonium regimen as induction agents for neonatal endotracheal intubation: a randomized, controlled trial. Pediatrics 2007 Jun;119(6): e1248-e1255.

(9) Loeliger M, Inder T, Cain S et al. Cerebral outcomes in a preterm baboon model of early versus delayed nasal continuous positive airway pressure. Pediatrics 2006 Oct;118(4): 1640-1653.

(10) Thomson MA, Yoder BA, Winter VT et al. Delayed extubation to nasal continuous positive airway pressure in the immature baboon model of bronchopulmonary dysplasia: lung clinical and pathological findings. Pediatrics 2006 Nov;118(5): 20382050 . 
(11) Victorin LH, Deverajan LV, Curstedt T et al. Surfactant replacement in spontaneously breathing babies with hyaline membrane disease--a pilot study. Biol Neonate 1990;58(3): 121-126.

(12) Bohlin K, Gudmundsdottir T, Katz-Salamon M et al. Implementation of surfactant treatment during continuous positive airway pressure. J Perinatol 2007 Jul;27(7): 422427.

(13) Verder H, Robertson B, Greisen G et al. Surfactant therapy and nasal continuous positive airway pressure for newborns with respiratory distress syndrome. DanishSwedish Multicenter Study Group. N Engl J Med 1994 Oct 20;331(16): 1051-1055.

(14) Kart T, Christrup LL, Rasmussen M. Recommended use of morphine in neonates, infants and children based on a literature review: Part 1--Pharmacokinetics. Paediatr Anaesth 1997;7(1): 5-11.

(15) Anand KJ, Anderson BJ, Holford NH et al. Morphine pharmacokinetics and pharmacodynamics in preterm and term neonates: secondary results from the NEOPAIN trial. Br J Anaesth 2008 Nov;101(5): 680-689.

(16) Deshpande G, Gill A. Cardiac arrest following naloxone in an extremely preterm neonate. Eur J Pediatr 2009 Jan;168(1): 115-117.

(17) Taeusch, Ballard, Avery. Diseases of The Newborn, Sixth edn Schaffer \& Avery`s, 1991:501.

(18) Benveniste D, Berg O, Pedersen JE. A technique for delivery of continuous positive airway pressure to the neonate. J Pediatr 1976 Jun;88(6): 1015-1019.

(19) Steyn MP, Quinn AM, Gillespie JA et al. Tracheal intubation without neuromuscular block in children. Br J Anaesth 1994 Apr;72(4): 403-406.

(20) Schrum SF, Hannallah RS, Verghese PM et al. Comparison of propofol and thiopental for rapid anesthesia induction in infants. Anesth Analg 1994 Mar;78(3): 482-485.

(21) Valtonen M, Iisalo E, Kanto J et al. Comparison between propofol and thiopentone for induction of anaesthesia in children. Anaesthesia 1988 Aug;43(8): 696-699.

(22) Veyckemans F. Propofol for intubation of the newborn? Paediatr Anaesth 2001;11(5): 630-631.

(23) Vespasiano M, Finkelstein M, Kurachek S. Propofol sedation: intensivists' experience with 7304 cases in a children's hospital. Pediatrics 2007 Dec;120(6): e1411-e1417.

(24) Papoff P, Mancuso M, Caresta E et al. Effectiveness and safety of propofol in newborn infants. Pediatrics 2008 Feb;121(2): 448-449.

(25) Batton B, Batton D, Riggs T. Blood pressure during the first 7 days in premature infants born at postmenstrual age 23 to 25 weeks. Am J Perinatol 2007 Feb;24(2): 107-115. 
(26) Kent AL, Meskell S, Falk MC et al. Normative blood pressure data in non-ventilated premature neonates from 28-36 weeks gestation. Pediatr Nephrol 2009 Jan;24(1): 141-146.

(27) Kam PC, Cardone D. Propofol infusion syndrome. Anaesthesia 2007 Jul;62(7): 690701.

(28) Marik PE. Propofol: therapeutic indications and side-effects. Curr Pharm Des 2004;10(29): 3639-3649.

(29) Williams GD, Jones TK, Hanson KA et al. The hemodynamic effects of propofol in children with congenital heart disease. Anesth Analg 1999 Dec;89(6): 1411-1416.

(30) Allegaert K, de Hoon J, Verbesselt R et al. Maturational pharmacokinetics of single intravenous bolus of propofol. Paediatr Anaesth 2007 Nov;17(11): 1028-1034. 


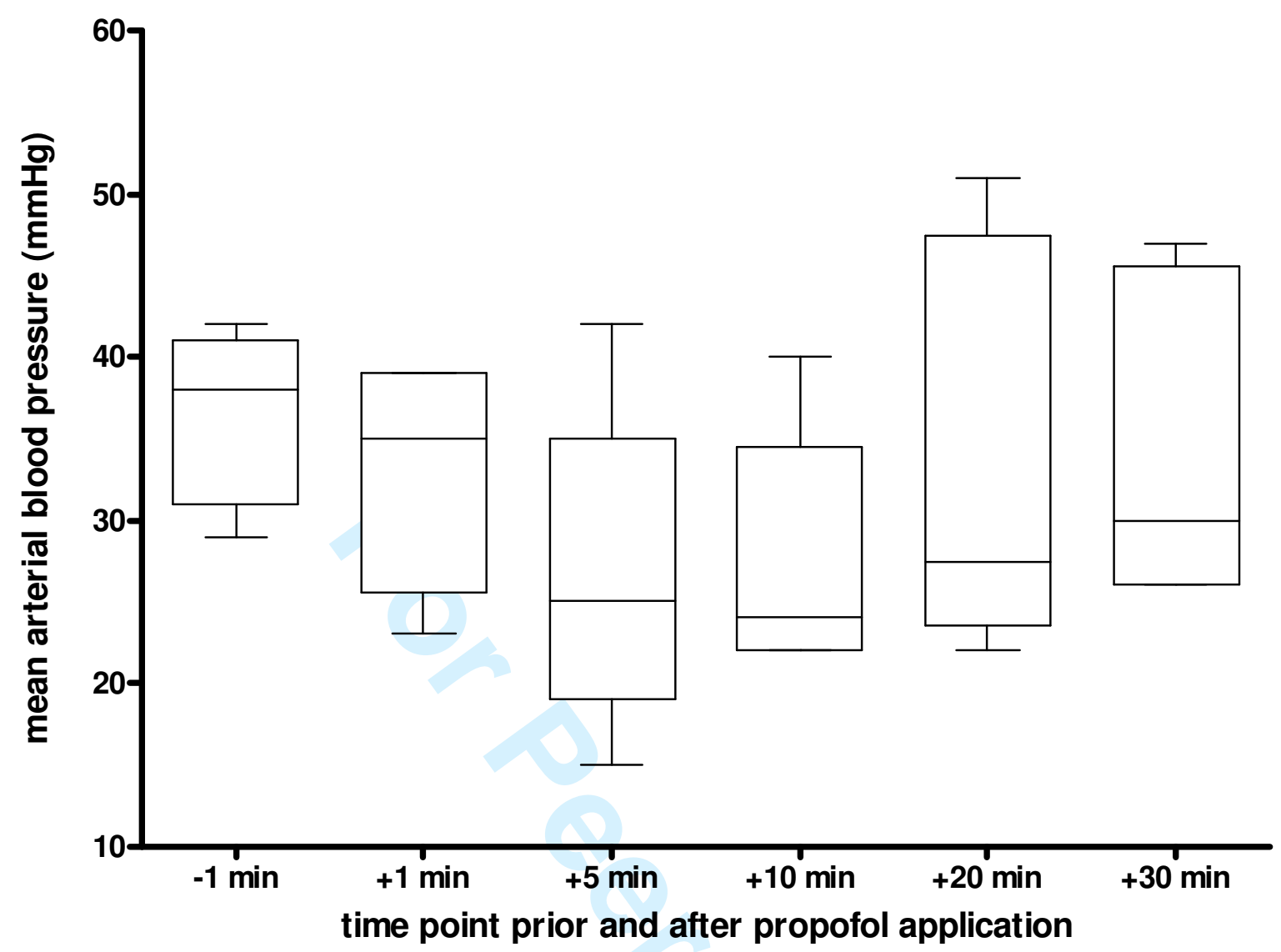

\section{Figure 1:}

A propofol bolus dose of $1 \mathrm{mg} / \mathrm{kg}$ caused significant arterial hypotension with mean arterial blood pressure decreasing from $38 \mathrm{mmHg}$ to $24 \mathrm{mmHg}$ within ten minutes after propofol administration. Even after thirty minutes the blood pressure had still not returned to initial values $(n=6)$. 


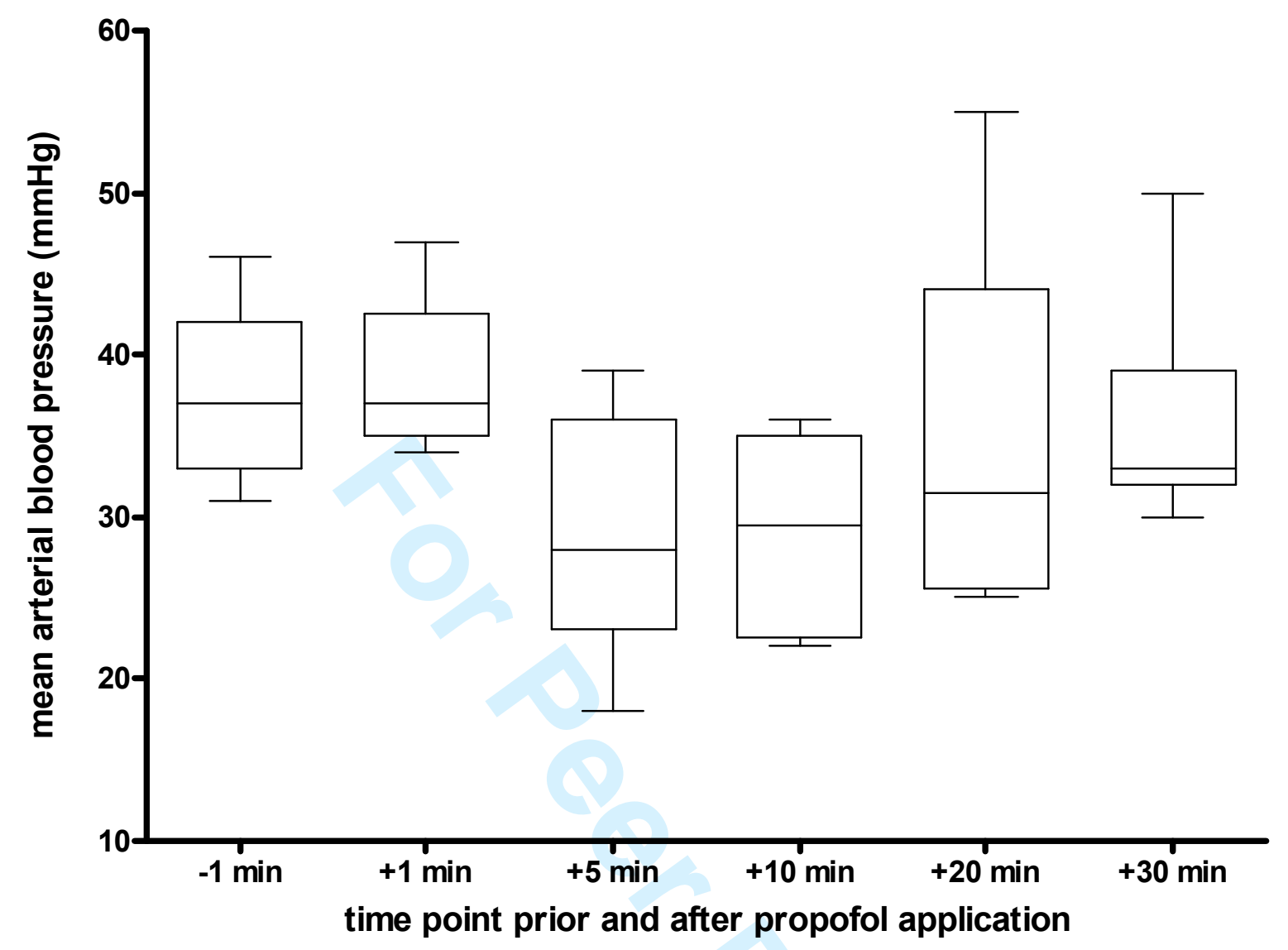

Figure 2:

A propofol dose of $1 \mathrm{mg} / \mathrm{kg}$ applied over 60 seconds also caused significant arterial hypotension with mean arterial blood pressure decreasing from $37 \mathrm{mmHg}$ to $28 \mathrm{mmHg}$ within five minutes after propofol administration $(n=7)$. 


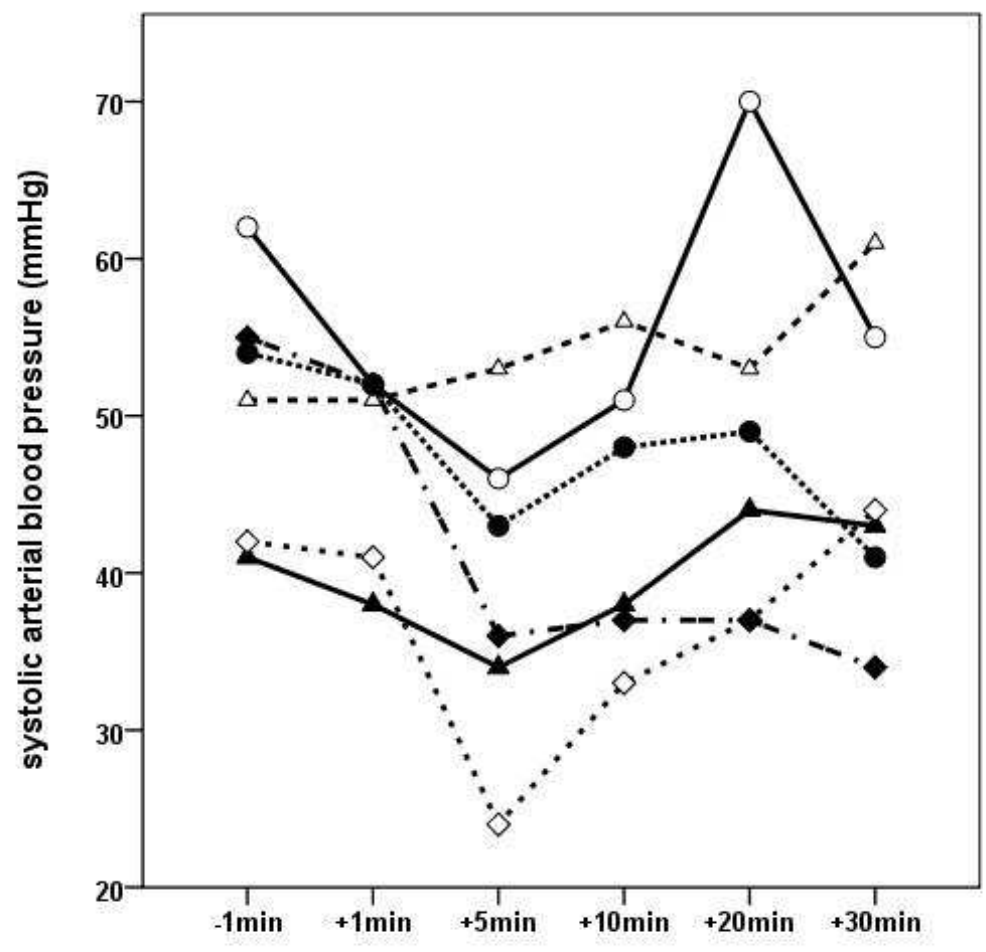

time point prior and after propofol application

Figure 3:

Systolic arterial blood pressure following a propofol bolus dose of $1 \mathrm{mg} / \mathrm{kg}(\mathrm{n}=6)$. Systolic arterial blood pressure remained stable in some infants, while there was a decrease to $24 \mathrm{mmHg}$ in the most severe case of arterial hypotension. 


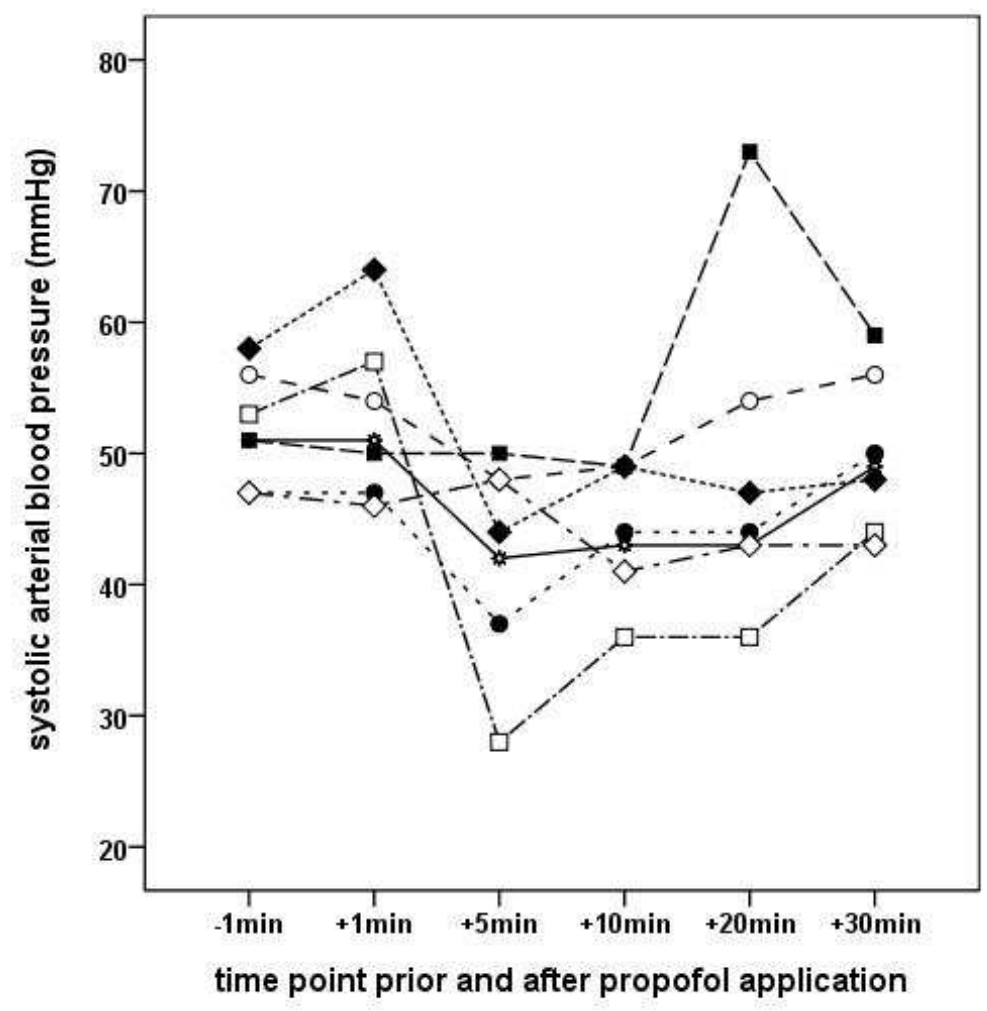

Figure 4:

Systolic arterial blood pressure following a propofol dose of $1 \mathrm{mg} / \mathrm{kg}$ applied over 60 seconds $(\mathrm{n}=$ 7). Again systolic arterial blood pressure remained stable in some infants, while there was a pronounced decrease to $28 \mathrm{mmHg}$ in the most severe case of arterial hypotension. 


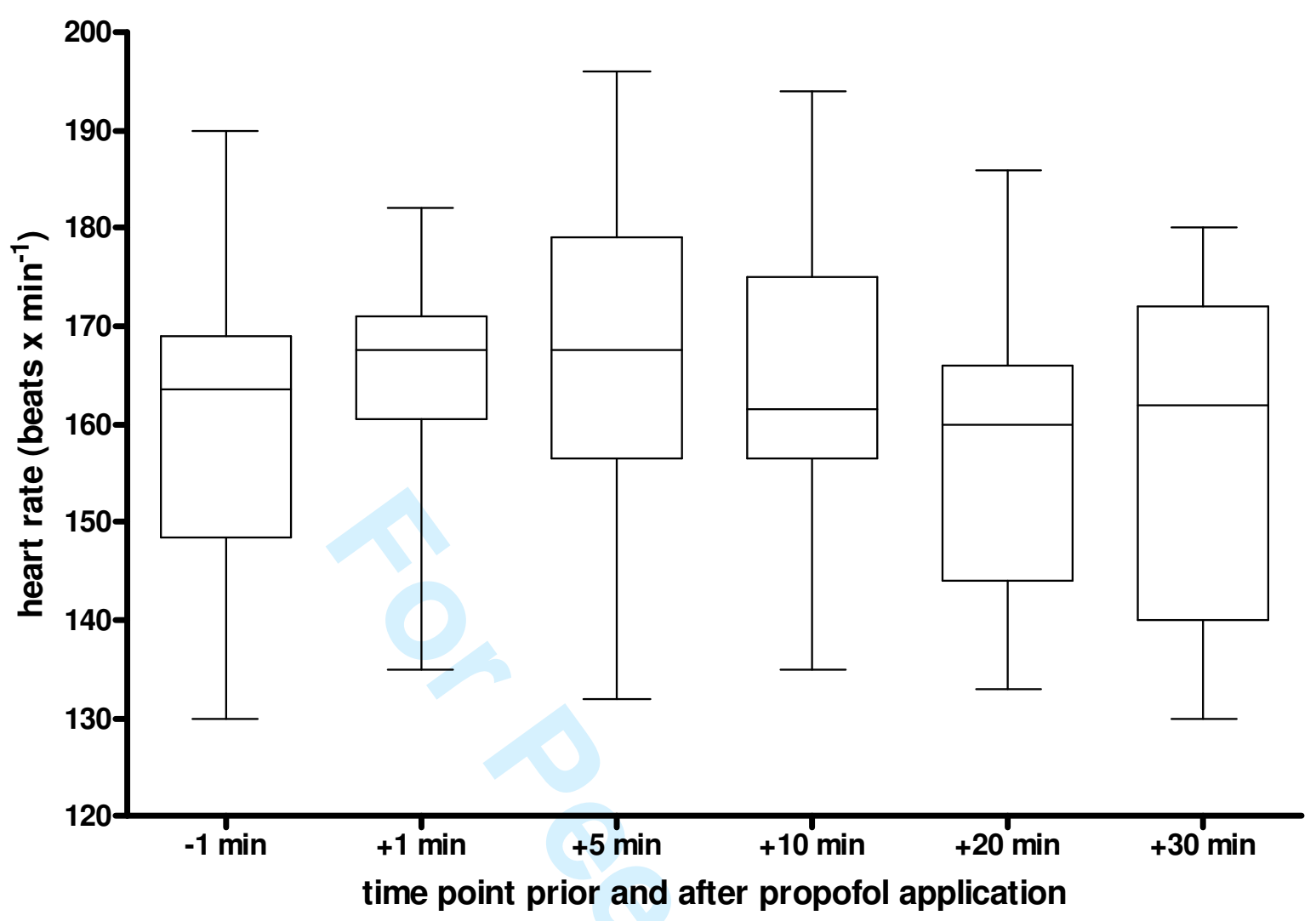

\section{Figure 5:}

In all patients heart rate remained stable after propofol application $(n=13)$. 


\section{Table 1}

Assessment of intubating conditions $(\mathrm{n}=13)$

\begin{tabular}{|c|c|c|c|}
\hline variable & $\begin{array}{c}\text { none } \\
\text { score }=0 \\
(\mathrm{n})\end{array}$ & $\begin{array}{c}\text { mild } \\
\text { score }=1 \\
(\mathrm{n})\end{array}$ & $\begin{array}{c}\text { distinct } \\
\text { score }=2 \\
(\mathrm{n})\end{array}$ \\
\hline limb movements & 6 & 7 & 0 \\
\hline coughing/retching & 9 & 2 & 2 \\
\hline breathing & 3 & 10 & 0 \\
\hline
\end{tabular}

Intubating conditions were judged excellent when total score was $\leq 1$ and good when total score was 2-3. Any assessment score $>3$, distinct limb movements or distinct coughing were taken as indicative of inadequate conditions. 